\title{
Assessment of left atrial structural remodeling in patients with cryptogenic stroke - lessons learned from LGE-MRI
}

Christian Mahnkopf*, Marcel Mitlacher, Johannes Brachmann

From 19th Annual SCMR Scientific Sessions

Los Angeles, CA, USA. 27-30 January 2016

\section{Background}

Cryptogenic embolic strokes of undetermined source (ESUS) are thought to comprise about 25\% of all ischemic strokes. Late-Gadolinium MRI (LGE-MRI) allows detection and quantification of left atrial structural remodeling (LA-SRM). We sought to compare the degree of LA-SRM using LGE-MRI in patients with ESUS and in patients

with embolic stroke of know origin, especially in those with atrial fibrillation (AFIB).

\section{Methods}

A total of fifty patients (31male (62\%), Age $61.1 \pm 14.2$ years) with TIA or Stroke underwent LGE-MRI of the left atrium within 4 days after the event to assess for

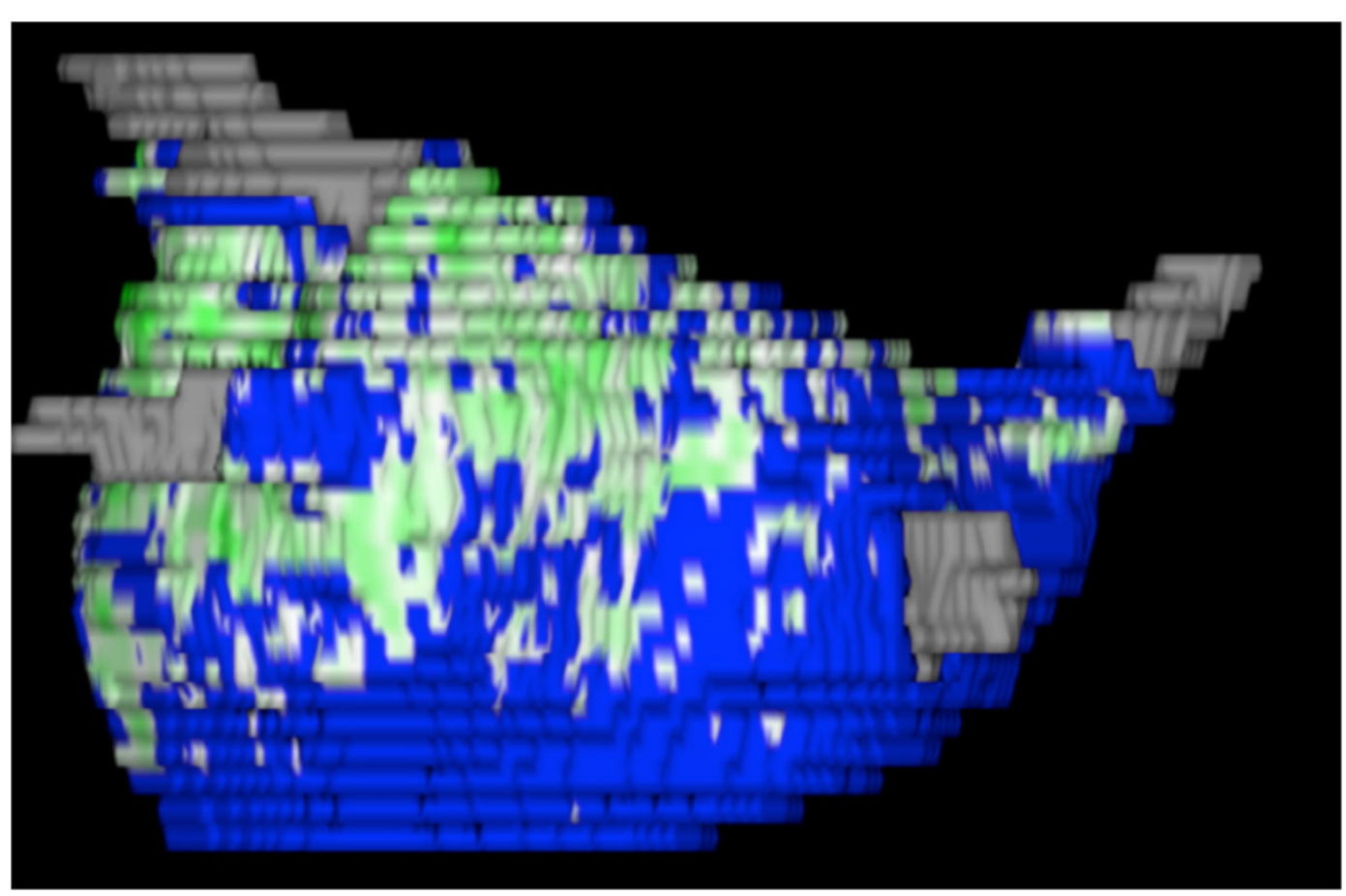

Figure 1 3D-Model of the left atrium. Example of a patient with extensive LA-SRM. Blue reflects healthy LA-tissue, while fibrotic areas are given in green. Pulmonary veins in great. PA-view (Merisight TM). 


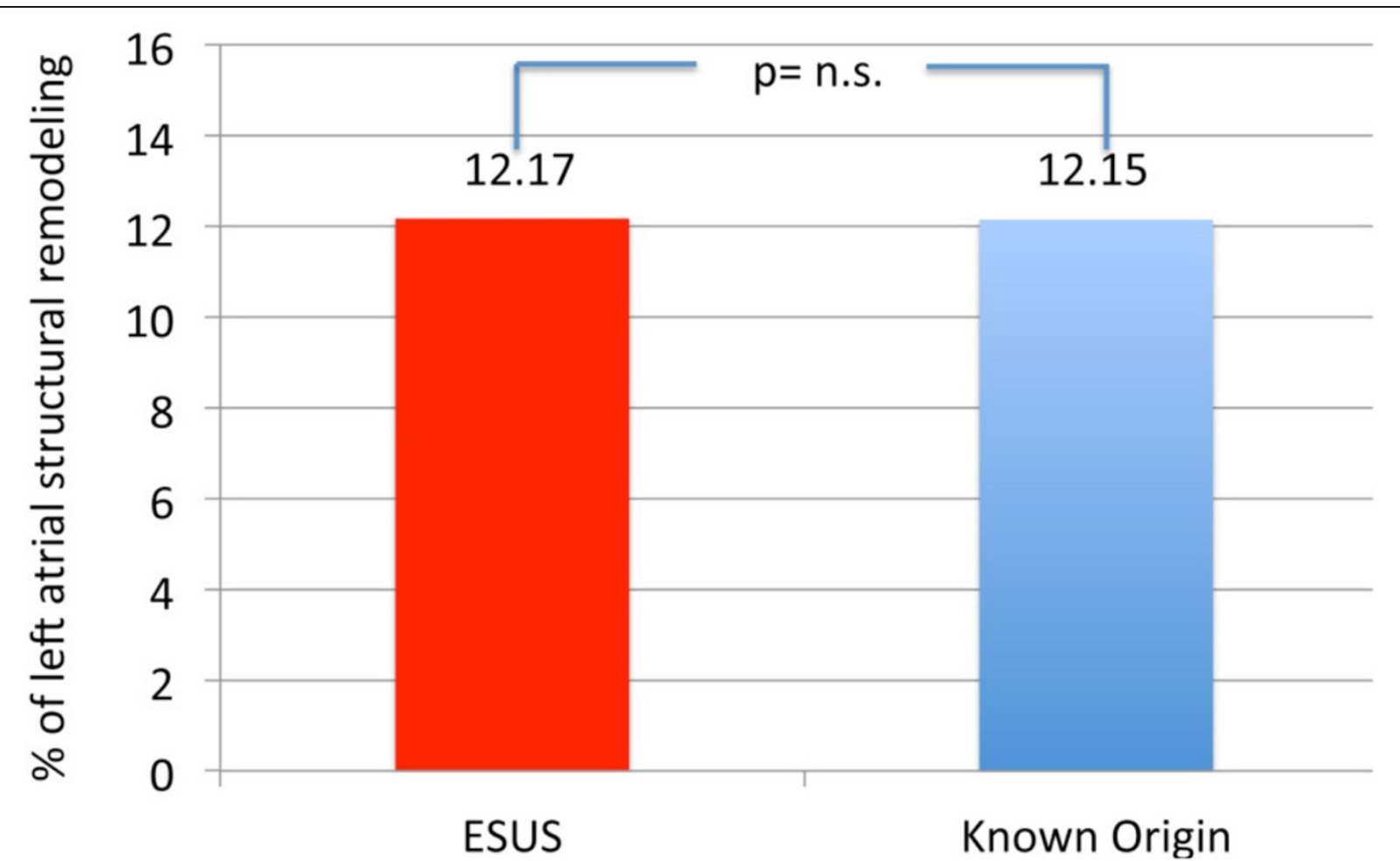

Figure 2 Degree of LA-SRM in patients with embolic strokes of undetermined source (red column) and in patients with stroke of known origin (blue column).

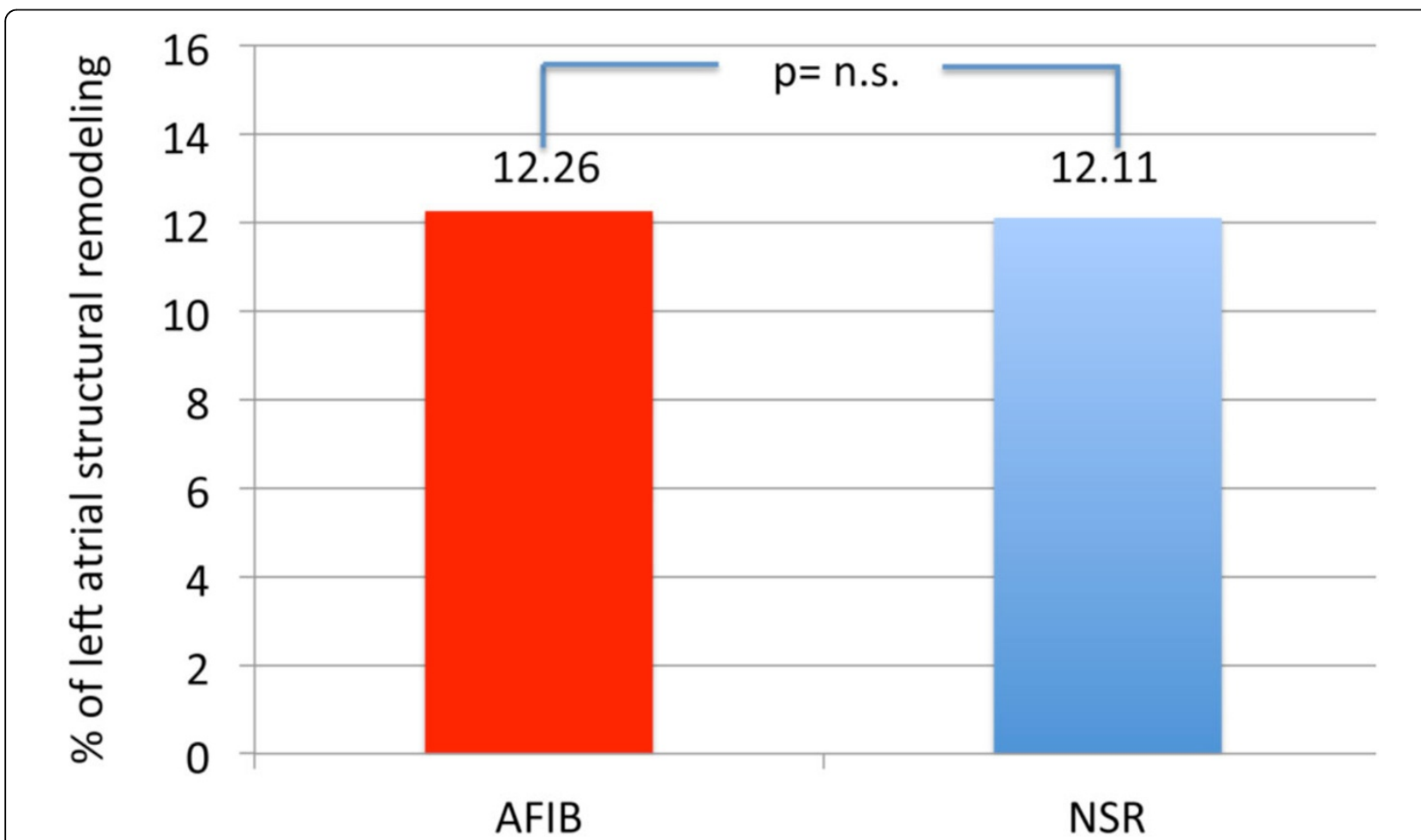

Figure 3 Degree of LA-SRM in patients with embolic stroke and atrial fibrillation (red column) and in embolic stroke patients with normal sinus rhythm (blue column). 
LA-SRM. Each LGE-MRI was segmented by isolating the LA wall and quantified for the relative extent of fibrotic remodeling using the Corview-Software (Merisight TM, Figure 1). Brain-CT or MRI, TEE, Sonography of the cerebral blood vessels and 24 hour ECG were performed in all patients.

\section{Results}

A total of 24 patients (48\%) were specified with the diagnosis of ESUS, while a reason for the stroke event (AFIB, significant carotids stenosis, LAA-thrombus, persistent foramen ovale) was found in 26 patients (52\%). The degree of left atrial remodeling was comparable in both groups $(12.17 \pm 5.23$ vs. $12.15 \% \pm 5.46 \% ; p=0.993$; Figure 2$)$. Overall, 15 patients $(30 \%, 11$ males) had a history of or were currently found with atrial fibrillation as a major reason for embolic stroke. Degree of LA-SRM $(12.26 \% \pm$ 6.4\%) was comparable to those stroke patients with sinus rhythm (12.11 \pm 4.85 , p=n.s., Figure 3$)$.

\section{Conclusions}

From our preliminary results the degree of left atrial structural remodeling detected using LGE-MRI is comparable in patients with know origin of stroke and in those with so-called cryptogenic stroke. Thus, the extent of LA-SRM appears to play a critical role in the pathophysiology of embolic stroke and should be considered in the diagnosis, treatment, and risk stratification in stroke patients.

Published: 27 January 2016
Submit your next manuscript to BioMed Central and take full advantage of:

- Convenient online submission

- Thorough peer review

- No space constraints or color figure charges

- Immediate publication on acceptance

- Inclusion in PubMed, CAS, Scopus and Google Scholar

- Research which is freely available for redistribution

Submit your manuscript at www.biomedcentral.com/submit 